\title{
Duration of adjuvant treatment following radical resection of metastases from gastrointestinal stromal tumours
}

\author{
MARGHERITA NANNINI $^{1}$, MARIA ABBONDANZA PANTALEO ${ }^{1,2}$, ALESSANDRA MALEDDU $^{1}$, \\ MARISTELLA SAPONARA ${ }^{1}$, ANNA MANDRIOLI ${ }^{1}$, CRISTIAN LOLLI ${ }^{1}$, MARIA CATERINA PALLOTTI ${ }^{1}$, \\ LIDIA GATTO $^{1}$, DONATELLA SANTINI ${ }^{3}$, PAOLA PATERINI ${ }^{2}$, VALERIO DI SCIOSCIO ${ }^{4}$, FAUSTO CATENA ${ }^{5}$, \\ PIETRO FUSAROLI ${ }^{6}$, ANTONIO DANIELE PINNA ${ }^{5}$, ANGELO PAOLO DEI TOS ${ }^{7}$ and GUIDO BIASCO ${ }^{1,2}$ \\ ${ }^{1}$ Department of Hematology and Oncology Sciences 'L.A. Seragnoli', S.Orsola-Malpighi Hospital; \\ ${ }^{2}$ Interdepartmental Centre for Cancer Research 'G. Prodi'; ${ }^{3}$ Pathology Unit, S.Orsola-Malpighi Hospital; \\ ${ }^{4}$ Division of Pneumo-Nefro, Department of Radiology, University Hospital S.Orsola-Malpighi; \\ ${ }^{5}$ Transplant, General and Emergency Surgery Department, S. Orsola-Malpighi Hospital, University of Bologna, \\ Bologna; ${ }^{6}$ Department of Clinical Medicine, GI Unit, University of Bologna/AUSL of Imola, Imola; \\ ${ }^{7}$ Department of Oncology, Anatomic Pathology, General Hospital of Treviso, Treviso, Italy
}

Received September 16, 2011; Accepted December 9, 2011

DOI: $10.3892 / 01.2011 .537$

\begin{abstract}
Large-scale studies have demonstrated that continuative treatment in advanced and adjuvant settings results in a gain-of-survival. However, the discontinuation, and the duration of treatment in disease-free patients who have undergone radical surgical resection of metastases from gastrointestinal stromal tumours (GISTs) have yet to be evaluated. We retrospectively reviewed 40 patients with advanced and recurrent GIST, included in our GIST database, focusing on patients (5 males and 2 females; median age 56 years) who continued medical treatment following radical surgical resection of metastatic lesions. Seven out of 40 patients underwent surgery and continued medical treatment following radical surgical resection of metastatic lesions. The duration of adjuvant therapy was $3,12,16,24,35,37$ and 52 months, respectively, with a median of 26 months. No patients discontinued therapy and all were disease-free at the final CT-scan evaluation. Considering that the discontinuation of imatinib in responding patients with advanced GIST (even in complete remission) results in a rapid high risk of progression, and a short adjuvant therapy results in a shorter disease-free and overall survival in highrisk GIST patients, it is also likely that treatment should not be discontinued in this setting. However, large-scale studies are required to better assess the optimal duration of treatment,
\end{abstract}

Correspondence to: Dr Margherita Nannini, Department of Hematology and Oncology Sciences 'L.A. Seràgnoli', S.OrsolaMalpighi Hospital, University of Bologna, Via Massarenti 9, I-40138 Bologna, Italy

E-mail: maggie.nannini@gmail.com

Key words: gastrointestinal stromal tumours, KIT, platelet-derived growth factor receptor, imatinib, adjuvant therapy, discontinuation, tyrosine-kinase inhibitors particularly after 5 years, by focusing on the identification of predictive factors for the selection of patients who may benefit from a prolonged or lifelong imatinib treatment.

\section{Introduction}

In the last ten years the introduction of imatinib, a small tyrosine-kinase inhibitor (TKI), selective for KIT and platelet-derived growth factor receptor (PDGFRA), has markedly modified the natural history of gastrointestinal stromal tumours (GISTs). Imatinib is the worldwide standard treatment for non-operable/advanced/recurrent disease and, more recently, for patients with a substantial risk of relapse (1-3).

The discontinuation of treatment in advanced disease, even in patients who have achieved a radiological complete remission, is not recommended unless severe toxicity occurs, since imatinib interruption results in a high risk of rapid progression (4-6).

In the adjuvant setting, the current recommendation is the use of imatinib for 1 year, although 3 years of administration compared to 1 year recently led to an improvement in relapse-free and overall survival in GIST patients with a high estimated risk of recurrence following surgery (3).

Whereas large-scale studies have shown that continuative treatment in advanced and adjuvant settings results in a gain-of-survival, the discontinuation, and thus the duration of treatment, in disease-free patients who underwent radical surgical resection of metastatic GISTs has yet to be investigated.

Currently, ESMO clinical practice guidelines recommend that patients with advanced/recurrent GIST responding to imatinib should continue treatment indefinitely, even in the postoperative setting, with an evidence level of II (7).

The present study reports on the long-term outcome of patients from S.Orsola-Malpighi Hospital (Italy) who continued medical treatment following radical surgical resection of advanced/metastatic GISTs. 


\section{Materials and methods}

Patients. We retrospectively reviewed 40 patients with advanced and recurrent GIST, included in our GIST database, focusing on patients who continued medical treatment following radical surgical resection of metastatic lesions. Of the 40 patients with advanced or recurrent GIST, 7 patients received surgery and continued medical treatment following radical surgical resection of metastatic lesions. Patient characteristics are shown in Table I. The group comprised 5 (71\%) males and 2 (29\%) females. Age had a unimodal distribution, with a median of 56 years (range, 30-68). The primary tumour site was the stomach in 6 patients $(86 \%)$ and small intestine in 1 patient (14\%).

Primary tumour risk stratification was defined according to the NIH and Miettinen classifications $(8,9)$. According to Miettinen's classification, risk stratification included the following: 5 patients (71\%) had a high-risk tumour, 1 patient (14.5\%) had an intermediate-risk tumour and 1 patient (14.5\%) had a low-risk tumour. The sites of metastasis were the liver in 4 patients (57.1\%), peritoneum in 1 patient (14.3\%), liver and peritoneum in 1 patient (14.3\%) and liver and lymph nodes in 1 patient $(14.3 \%)$.

Four patients had advanced GIST at the time of diagnosis, whereas 3 patients relapsed 10,35 and 39 months, respectively, following primary tumour resection.

Methods. Mutational analysis of KIT and PDGFRA was performed on genomic DNA extracted from paraffin-embedded tumour tissue by KIT Qiagen (QiAamp DNA FFPE Tissue Kit) using a combination of polymerase chain reaction (PCR) amplification and automated sequencing. The mutational analysis only on primary GIST tumours was performed in 6 out of 7 patients: 4 patients harboured a KIT exon 11 mutation, 1 patient harboured a PDGFRA exon 18 mutation and 1 patient had a wild-type (WT) GIST. Among these patients, the mutational analysis on metastases was performed only in 2 patients and exhibited the same mutational status of the primary GIST, whereas in 2 patients mutational analysis was not achievable due to huge necrosis following medical treatment, and in the other 2 patients the biological samples were not available. In the only remaining patient (patient 1 ) where the mutational analysis was not carried out on the primary GIST tumour, it was performed on the metastatic tissue and the result was a KIT exon 11 mutation associated to a secondary exon 17 mutation (Table II).

\section{Results}

Findings of CT-PET scan and CT scan. Seven patients underwent radical surgical resection of metastases from GIST. Of 4 patients with advanced GIST at the time of diagnosis, 3 were treated with primary tumour excision followed by imatinib (400 mg daily) as first-line treatment for the metastases, while the remaining patient underwent radical primary tumour and metastases excision up-front. Of 3 patients with recurrent GIST, 2 were treated with imatinib ( $400 \mathrm{mg}$ daily) as first-line treatment, while the remaining patient underwent surgical excision of the metastatic lesions up-front. The duration of first-line treatment with imatinib (400 mg daily) was 16,19
Table I. Patient characteristics.

Number of patients

Total $(\mathrm{n}=7)$

\begin{tabular}{lc}
\hline Gender & \\
Male & $5(71 \%)$ \\
Female & $2(29 \%)$ \\
Age (years) & \\
Median & 56 \\
Range & $30-68$ \\
Primary tumour site & \\
Stomach & $6(86 \%)$ \\
Small intestine & $1(14 \%)$ \\
Risk & \\
Low & $1(14.5 \%)$ \\
Intermediate & $1(14.5 \%)$ \\
High & $5(71 \%)$ \\
Stage at time of diagnosis & \\
Localised & $3(37.5 \%)$ \\
Advanced & $4(62.5 \%)$ \\
Sites of metastasis & \\
Liver & $4(57.1 \%)$ \\
Peritoneum & $1(14.3 \%)$ \\
Liver and peritoneum & $1(14.3 \%)$ \\
Liver and lymph nodes & $1(14.3 \%)$
\end{tabular}

and 34 months in 3 advanced GIST patients, and 16 and 11 months in 2 recurrent GIST patients. Therefore, 5 patients received imatinib treatment at a dose of $400 \mathrm{mg}$ daily prior to the surgical removal of metastases, and 2 patients underwent surgery up-front without medical treatment. Of those 5 patients, 3 had an early complete response at CT-PET scan performed 7 days following start of therapy. Four patients underwent surgery at best radiological response assessed by CT scan, whereas only 1 patient (patient 1 ) received a secondline treatment with imatinib ( $800 \mathrm{mg}$ daily), due to disease progression, for a duration of 11 months, and then underwent surgery at best radiological response.

Following surgery, all 7 patients continued the same medical treatment received prior to surgical procedures without discontinuation for 3, 12, 16, 24, 35, 37 and 52 months, respectively, with a median of 26 months. The patients were disease-free at the final CT scan evaluation.

Pathological tumour response. Pathological tumour response was assessed in 4 out of 5 patients who received medical treatment prior to surgical removal of metastases of whom 3 had a high pathological response (tumour necrosis $>90 \%$ ) and 1 patient had a moderate pathological response (tumour necrosis: $50-90 \%$ ) according to criteria determined by Antonescu et al (10).

\section{Discussion}

Although the introduction of imatinib has changed the natural history of GIST, treatment duration in various settings of disease 
Table II. KIT and PDGFRA mutational analysis.

\begin{tabular}{|c|c|c|}
\hline Patient & Primary tumour & Metastases \\
\hline 1 & $\mathrm{NP}^{\mathrm{a}}$ & $\begin{array}{l}\text { c.1674_1695del KIT exon } 11 \\
\text { (p.Lys558_Gly565del) } \\
\text { c. T>A 2466 KIT exon } 17 \text { (p.Asn822 Lys) }\end{array}$ \\
\hline 2 & $\begin{array}{l}\text { PDGFRA exon } 18 \text { c.2523_2531del } \\
\text { (p.Asp842_Met844del) }\end{array}$ & $\mathrm{NP}^{\mathrm{b}}$ \\
\hline 3 & $\begin{array}{l}\text { KIT exon } 11 \text { c. } 1727 \mathrm{~T}>\mathrm{C} \\
\text { (p.Leu576Pro) }\end{array}$ & $\mathrm{NP}^{\mathrm{b}}$ \\
\hline 4 & $\begin{array}{l}\text { KIT exon } 11 \text { c.1669_1674 } \\
\text { (p.Trp557_Lys558) }\end{array}$ & $\begin{array}{l}\text { KIT exon } 11 \text { c.1669_1674 } \\
\text { (p.Trp557_Lys558) }\end{array}$ \\
\hline 5 & $\begin{array}{l}\text { KIT exon } 11.1669 \_1647 d e l \\
\text { (p.Trp557_Lys558) }\end{array}$ & $\mathrm{NP}^{\mathrm{a}}$ \\
\hline 6 & Wild-type & Wild-type \\
\hline 7 & KIT exon 11 delWK557-558 & $\mathrm{NP}^{\mathrm{a}}$ \\
\hline
\end{tabular}

${ }^{a} \mathrm{NP}$, not performed as tumour samples were not appropriate due to huge necrosis following medical treatment. ${ }^{\mathrm{b}} \mathrm{NP}$, not performed as tumour samples were not available. PDGFRA, platelet-derived growth factor receptor.

remain to be investigated. The imatinib-dependent selection of resistant tumour clones harbouring novel mutations, and the potential decline of quality of life due to a daily chronic therapy have questioned the duration of therapy, in advanced disease and, more recently, in radically resected limited disease.

In advanced disease the discontinuation of imatinib has been shown to result in a high risk of disease progression in responder patients with advanced GIST (4-6). In particular, imatinib interruption following 3 years of treatment led to a rapid progression, with a median progression-free survival of only 9 months (4). However, the difference in progression-free and overall survival between patients in the interruption group who resumed imatinib at the time of progression and patients in the continuation group was not statistically significant, even if imatinib re-introduction re-established tumour control in the majority of, but not all, patients $(4,5)$.

The same finding has also been reported in patients with chronic myeloid leukaemia (CML) in complete molecular remission for at least 2 years: $61 \%$ of patients who discontinued treatment had a molecular relapse following a median follow-up of 21 months (11). Therefore, these data, confirmed in various tyrosine kinase-driven malignancies, including GIST and CML, suggest that imatinib is unable to eradicate microscopic residual tumour clones in patients who achieved a complete remission. Thus, imatinib alone is unable to cure patients with advanced GIST, even in radiological complete remission; therefore, in this setting medical treatment should be prolonged until progression or intolerance (7).

Furthermore, a subset of patients with advanced GIST survived over 9 years with continuous imatinib therapy, without unexpected long-term toxicities (12). Among 147 patients with advanced GIST initially enrolled in the first large trial B2222, 26 patients $(17.7 \%)$ remained on continuous imatinib from study entry (12). Low tumour bulk at baseline was identified as a predictive factor for longer time to progression and improved overall survival (12).
Moving to the adjuvant setting, the recent results from the SSGXVIII/AIO trial have demonstrated that 3 years of imatinib administration as adjuvant treatment for GIST patients at a high risk of recurrence following surgery led to an improvement in relapse-free and overall survival compared to 1 year of treatment (3). According to these data, patients with minimal residual disease may also benefit from a prolonged treatment with imatinib, suggesting that patients with a substantial risk of GIST are eligibile for long-term therapy.

By contrast, the discontinuation of treatment in disease-free patients following radical surgical resection of advanced/metastatic GIST has not yet been investigated. Thus, the duration of treatment in this specific setting remains to be elucidated.

It is now accepted that surgery for residual disease upon best clinical response is associated with survival benefits in certain retrospective studies (13-19). In particular, Mussi and colleagues recently reported a significant improvement in disease-specific survival in patients who underwent surgical resection of metastatic or recurrent GIST upon best response in comparison with historical controls treated with imatinib alone (13). In this study, the 7 patients who underwent surgical resection upon best response continued imatinib following surgery, with a 2-year progression-free survival rate of $64.4 \%$, suggesting that treatment interruption should be avoided even when lesions have been surgically excised (13).

We reported the long-term outcome of 7 patients from S.Orsola-Malpighi Hospital who continued medical treatment following radical surgical resection of advanced/metastatic GIST. The mean treatment duration was 26 months without discontinuation and all patients remained disease-free at the final CT evaluation. Three patients did not have evidence of disease after more than 3 years.

Despite the small case series, our report raises certain issues designed to open the debate on this topic. Considering that the discontinuation of imatinib in responder patients with advanced GIST, even in complete remission, results in 
a rapid high risk of progression, and a brief adjuvant therapy results in a shorter disease-free and overall survival in highrisk GIST patients, it is also likely that treatment should not be discontinued in this setting. Adjuvant imatinib treatment in GIST patients following surgical removal of metastases is well consolidated in clinical practice although no prospective trials are available. By contrast, the role of adjuvant chemotherapy in other diseases, such as colorectal cancer, following complete resection of metastases remains under debate and its use is still restricted in clinical practice due to the lack of consistent clinical trials supporting its benefit with regards to progression-free and overall survival $(20,21)$.

However, the optimal duration of treatment, particularly in patients with no evidence of disease after 5 or more years of therapy is likely to remain controversial for as long as the optimal duration of adjuvant therapy remains undefined.

Furthermore, novel risk stratification systems are essential for this subset of patients to select those patients that may benefit from treatment discontinuation. New nomograms for the prediction of recurrence-free survival following surgery for GIST-presenting risk of recurrence as a continuous scale have recently been proposed (22). However, the incorporation of other biological variables may increase the precision of these systems, particularly if applied to a complex subset of patients with an intrinsic high risk of recurrence, since they have already relapsed.

Three patients in our small series had a high pathological tumour response, and 1 had a moderate pathological tumour response to treatment received prior to the surgical removal of metastases. This finding suggests that pathological tumour response to pre-operative therapies exhibits a predictive value of recurrence-free survival following the radical surgery of metastases from GIST. In addition, the data on molecular analysis should be considered. In our series, 6 out of 7 patients have KIT/PDGFRA-sensitive mutations to imatinib in primary GIST tumours. In particular, the only patient who was resistant to imatinib (400 mg daily) harboured a KIT exon 11 mutation associated to a KIT exon 17 secondary mutation on the metastases, and experienced a tumour response following imatinib dose escalation to $800 \mathrm{mg} /$ day. Only 1 patient underwent radical primary tumour and metastases excision up-front and has a WT GIST that, as far as is known, may be less sensitive to imatinib. However, since the patient was 29 years of age and exhibited a high risk of recurrence, imatinib treatment was commenced.

The risk of selecting novel tumour clones harbouring resistant mutations during a prolonged treatment may be higher in patients who had metastatic disease, even if it has not been demonstrated that long-term exposure to TK inhibitors affects the development of secondary resistance mechanisms.

Finally, the subjective compliance with a chronic treatment may interfere with the assessment of optimal treatment duration in each clinical setting. It is noteworthy that in the SSGXVIII/AIO trial, the proportion of patients who discontinued imatinib during the assigned treatment period not due to disease recurrence was $25.8 \%$ in the 36 -month group in comparison to $12.6 \%$ in the 12 -month group (3).

In conclusion, the optimal duration of treatment in disease-free patients undergoing radical surgical resection of metastatic GIST has not yet been established. Highlighting recent evidence on imatinib discontinuation in complete remission advanced GIST patients, it is probable that treatment interruption should also be avoided following radical surgical excision of metastatic lesions. However, the duration of treatment in this particular clinical setting remains to be investigated and the decision to suspend treatment should be taken with the individual patient, particularly after 5 years.

Large-scale retrospective studies are required to evaluate the outcome of disease-free patients undergoing radical surgical resection of metastatic GIST following treatment discontinuation. Furthermore, novel molecular biomarkers must be identified to select those patients with a higher risk of relapse, who may benefit from prolonged or lifelong imatinib treatment.

\section{References}

1. Demetri GD, von Mehren M, Blanke CD, van den Abbeele AD, Eisenberg B, Roberts PJ, Heinrich MC, Tuveson DA, Singer S, Janicek M, et al: Efficacy and safety of imatinib mesylate in advanced gastrointestinal stromal tumors. N Engl J Med 347: 472-480, 2002.

2. Dematteo RP, Ballman KV, Antonescu CR, Maki RG, Pisters PW, Demetri GD, Blackstein ME, Blanke CD, von Mehren M, Brennan MF, et al; American College of Surgeons Oncology Group (ACOSOG) Intergroup Adjuvant GIST Study Team: Adjuvant imatinib mesylate after resection of localised, primary gastrointestinal stromal tumour: a randomised, double-blind, placebo-controlled trial. Lancet 373: 1097-1104, 2009.

3. Joensuu H, Eriksson M, Hatrmann J, Sundby Hall K, Schutte J, Reichardt M, Schlemmer M, Wardelmann E, Ramadori G, Al-Batran S, et al: Twelve versus 36 months of adjuvant imatinib (IM) as treatment of operable GIST with a high risk of recurrence: final results of a randomized trial (SSGXVIII/AIO). J Clin Oncol 29 (Suppl): LBA1, 2011.

4. Le Cesne A, Ray-Coquard I, Bui BN, Adenis A, Rios M, Bertucci F, Duffaud F, Chevreau C, Cupissol D, Cioffi A, et al; French Sarcoma Group: Discontinuation of imatinib in patients with advanced gastrointestinal stromal tumours after 3 years of treatment: an open-label multicentre randomised phase 3 trial. Lancet Oncol 11: 942-949, 2010.

5. Blay JY, Le Cesne A, Ray-Coquard I, Bui B, Duffaud F, Delbaldo C, Adenis A, Viens P, Rios M, Bompas E, et al: Prospective multicentric randomized phase III study of imatinib in patients with advanced gastrointestinal stromal tumors comparing interruption versus continuation of treatment beyond 1 year: the French Sarcoma Group. J Clin Oncol 25: 1107-1113, 2007.

6. Lee JL, Ryu MH, Chang HM, Kim TW, Kang HJ, Sohn HJ, Lee JS and Kang YK: Clinical outcome in gastrointestinal stromal tumor patients who interrupted imatinib after achieving stable disease or better response. Jpn J Clin Oncol 36: 704-711, 2006.

7. Casali PG and Blay JY; ESMO/CONTICANET/EUROBONET Consensus Panel of Experts: Gastrointestinal stromal tumours: ESMO Clinical Practice Guidelines for diagnosis, treatment and follow-up. Ann Oncol 21 (Suppl 5): v98-v102, 2010.

8. Fletcher CD, Berman JJ, Corless C, Gorstein F, Lasota J, Longley BJ, Miettinen M, O'Leary TJ, Remotti H, Rubin BP, Shmookler B, Sobin LH and Weiss SW: Diagnosis of gastrointestinal stromal tumors: a consensus approach. Hum Pathol 33: 459-465, 2002.

9. Miettinen M and Lasota J: Gastrointestinal stromal tumors: pathology and prognosis at different sites. Semin Diagn Pathol 23: 70-83, 2006.

10. Antonescu CR, Besmer P, Guo T, Arkun K, Hom G, Koryotowski B, Leversha MA, Jeffrey PD, Desantis D, Singer S, et al: Acquired resistance to imatinib in gastrointestinal stromal tumor occurs through secondary gene mutation. Clin Cancer Res 11: 4182-4190, 2005.

11. Mahon FX, Réa D, Guilhot J, Guilhot F, Huguet F, Nicolini F, Legros L, Charbonnier A, Guerci A, Varet B, et al; Intergroupe Français des Leucémies Myéloïdes Chroniques: Discontinuation of imatinib in patients with chronic myeloid leukaemia who have maintained complete molecular remission for at least 2 years: the prospective, multicentre Stop Imatinib (STIM) trial. Lancet Oncol 11: 1029-1035, 2010. 
12. von Mehren M,Heinrich M, Joensuu H, Blanke CD, Wehrle E and Demetri GD: Follow-up results after 9 years (yrs) of the ongoing, phase II B2222 trial of imatinib mesylate (IM) in patients (pts) with metastatic or unresectable KIT+ gastrointestinal stromal tumors (GIST). J Clin Oncol 29 (Suppl): 10016, 2011.

13. Mussi C, Ronellenfitsch U, Jakob J, Tamborini E, Reichardt P, Casali PG, Fiore M, Hohenberger P and Gronchi A: Post-imatinib surgery in advanced/metastatic GIST: is it worthwhile in all patients? Ann Oncol 21: 403-408, 2010.

14. Gronchi A, Fiore M, Miselli F, Lagonigro MS, Coco P, Messina A, Pilotti S and Casali PG: Surgery of residual disease following molecular-targeted therapy with imatinib mesylate in advanced/ metastatic GIST. Ann Surg 245: 341-346, 2007.

15. Hohenberger P, Schneider U, Pink D, Emmerich K, Kettelhack C, Roetschke $\mathrm{O}$ and Reichardt P: Resection of progressive or residual tumor after treatment with imatinib for advanced GI stromal tumors. Ann Surg Oncol 11 (Suppl): 53, 2004.

16. DeMatteo RP, Maki RG, Singer S, Gonen M, Brennan MF and Antonescu CR: Results of tyrosine kinase inhibitor therapy followed by surgical resection of metastatic gastrointestinal stromal tumor. Ann Surg 245: 347-352, 2007.

17. Bonvalot S, Eldweny H, Péchoux CL, Vanel D, Terrier P, Cavalcanti A, Robert C, Lassau N and Cesne AL: Impact of surgery on advanced gastrointestinal stromal tumors (GIST) in the imatinib era. Ann Surg Oncol 13: 1596-1603, 2006.

18. Rutkowski P, Nowecki Z, Nyckowski P, Dziewirski W, Grzesiakowska U, Nasierowska-Guttmejer A, Krawczyk M and Ruka W: Surgical treatment of patients with initially inoperable and/or metastatic gastrointestinal stromal tumors (GIST) during therapy with imatinib mesylate. J Surg Oncol 93: 304-311, 2006.
19. Raut CP, Posner M, Desai J, Morgan JA, George S, Zahrieh D, Fletcher CD, Demetri GD and Bertagnolli MM: Surgical management of advanced gastrointestinal stromal tumors after treatment with targeted systemic therapy using kinase inhibitors. J Clin Oncol 24: 2325-2331, 2006.

20. Mitry E, Fields AL, Bleiberg H, Labianca R, Portier G, Tu D, Nitti D, Torri V, Elias D, O'Callaghan C, et al: Adjuvant chemotherapy after potentially curative resection of metastases from colorectal cancer: a pooled analysis of two randomized trials. J Clin Oncol 26: 4906-4911, 2008.

21. Nordlinger B, Sorbye H, Glimelius B, Poston GJ, Schlag PM, Rougier P, Bechstein WO, Primrose JN, Walpole ET, Finch-Jones M, et al; EORTC Gastro-Intestinal Tract Cancer Group; Cancer Research UK; Arbeitsgruppe Lebermetastasen und-tumoren in der Chirurgischen Arbeitsgemeinschaft Onkologie (ALM-CAO); Australasian Gastro-Intestinal Trials Group (AGITG); Fédération Francophone de Cancérologie Digestive (FFCD): Perioperative chemotherapy with FOLFOX4 and surgery versus surgery alone for resectable liver metastases from colorectal cancer (EORTC Intergroup trial 40983): a randomised controlled trial. Lancet 371: 1007-1016, 2008.

22. Gold JS, Gönen M, Gutiérrez A, Broto JM, García-del-Muro X, Smyrk TC, Maki RG, Singer S, Brennan MF, Antonescu CR, Donohue JH and DeMatteo RP: Development and validation of a prognostic nomogram for recurrence-free survival after complete surgical resection of localised primary gastrointestinal stromal tumour: a retrospective analysis. Lancet Oncol 10: 1045-1052, 2009. 